\title{
TREATMENT NOTES
}

\section{SOME SUGGESTIONS IN THE REHABILITATION OF HEMIPLEGICS}

\author{
E. JENNINGS, M.C.S.P.
}

A. In Early Flaccid Stage:

(1) Teaching the patient to roll over by themselves onto their unaffected side.

Three actions:-

(a) Lifting the affected arm across the chest.

(b) Wriggling the toes of the unaffected side under the Tendo-Achilles of the other foot and so obtaining leverage to bring the affected leg over.

(c) Grasping the side of the bed towards which she wants to turn, and then pulling with the arm and leg and at the same time turning the head.

See Diagram I.

(2) Use of rope attached to the lower corners of the bed.

The length of this rope must be adjusted to be just long enough for the patient to reach with her outstretched unaffected hand. A padded area in the middle of the rope facilitates the grasp; this can be kept in position by adhesive strapping.

The patient should be given a crook stick to bring the rope within her reach.

Most patients will be able to sit up with the use of this rope within a few days.

N.B. A single centrally placed rope with a wooden handle is dangerous, as there is no side to side control.

See Diagram I.

(3) Foot Board.

This is a 4 " cubical piece of wood, 6" longer than the span between the legs of the bed. Two semicircular scallops are cut out of one side to fit against the legs of the bed and prevent it from slipping sideways.

\section{PROF. RAYMOND DART (continued from page 4)}

Thirdly, I have done it to show how words take on the meaning that we give to them by the sort of lives we lead, and also how inter-related all professional progress happens to be. There is a great tendency amongst immature human beings to imagine they increase their own importance not by self-improvement but by deriding others; or by insinuating that groups of workers other than their own particular class are of lesser value in the general scheme of things. You will often hear superficial thinkers say "Oh! what can she know about it? She's only a nurse", or, "How can he know? He's only a labourer, a shop assistant, a bricklayer, or what not". It was through doctors and nurses caring for the welfare and elevated status of all medical auxiliaries that led to what has been done so far for you and your education and through you for sick South Africans.

Finally, I hope that I have indicated, through what has lain behind and happened to your profession in South Africa during the past 40 years, something of the avalanching developments you can anticipate during the 40 years that now lie in front of you. Those developments are in your hands.

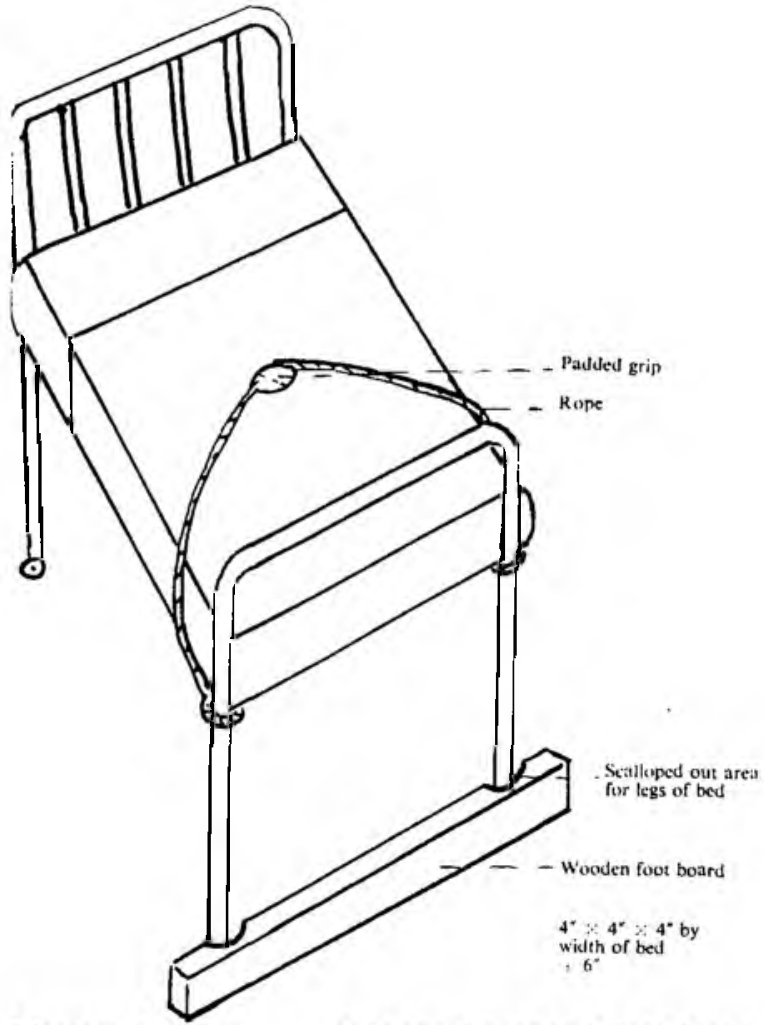

Diagram I

Rope attachment and Foot Board.

Use: The board is placed on the floor at either end of the bed (head preferably, for height). The patient is brought up to it in a chair and her feet are placed slightly apart against it on the ground. This prevents her weak leg from slipping under the bed and greatly assists the physiotherapist in her efforts to get the patient to stand up and sit down and to balance in standing. The patient of course pulls herself up, but the physiotherapist (standing on the affected side) holds the hand in position and encourages the patient to push upwards with both legs. The wooden bar also prevents the bed from moving.

\section{B. Walking Stage:}

As soon as the patient can balance herself in sitting and standing, walking is commenced. There are many methods; here are a few which I have found useful:-

(1) Assisting on the affected side. The patient supports herself in the parallel bars or on a hand-rail round the room.

N.B. Backward walking is almost as easy as forwards walking.

A chair is placed at either end of the bars.

The bars must be low enough for the patient to lean over slightly to the unaffected side.

See Diagram II 


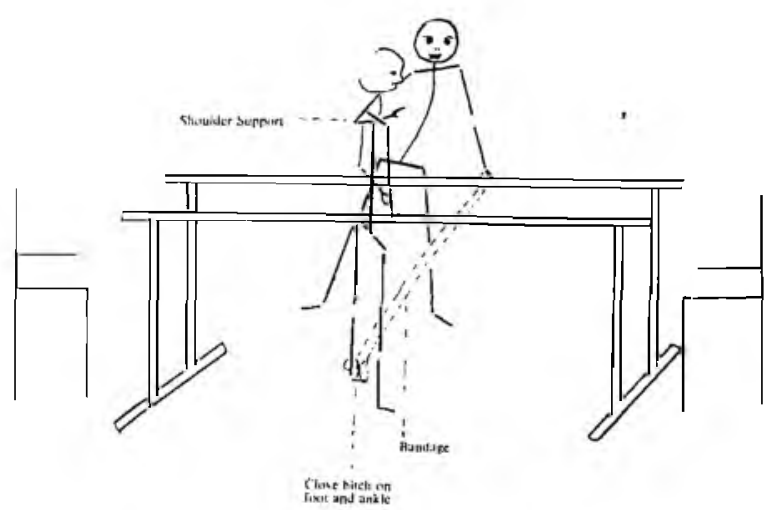

\section{Bandage Control}

Note wide and steady stance of physiotherapist who is pushing the patients weight onto her unaffected side.

\section{Diagram II}

If there is complete flaccidity or adduction spasticity a bandage may be tied with a clove-hitch around the foot and ankle, the long end being held in the physiotherapist's free hand. By this means excellent control of the leg, which tends to get behind the other foot and so prevent progress, can be obtained without the physiotherapist's having to change her position.

(2) Assisting on the affected side, walking round a table.

The patient's thumb over the edge makes the control.

\section{See Diagram III}

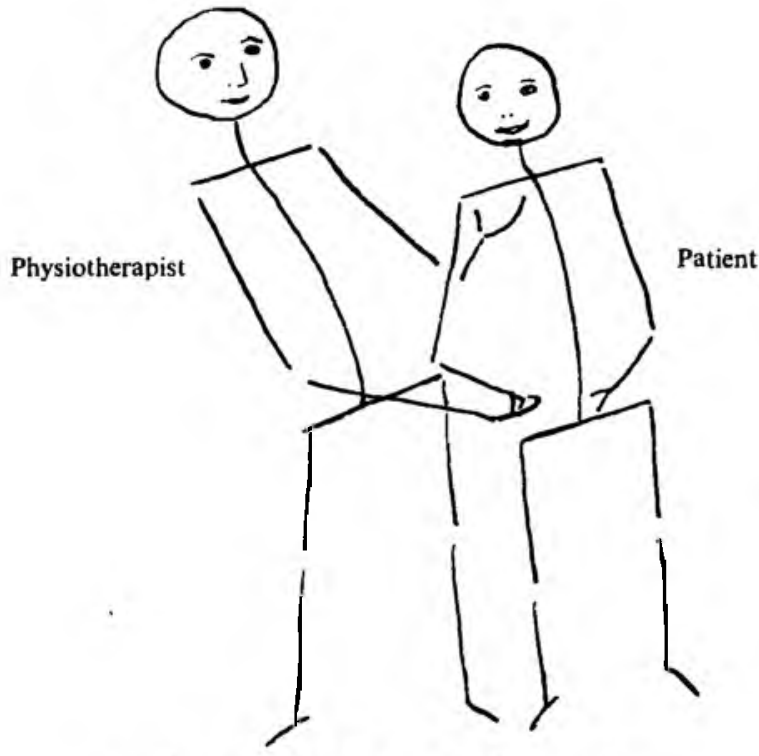

Assisted walking by one physiotherapist.

Note the counter-action of body weight by the physiotherapist who supports on the unaffected side. Bandage Control.
(3) Assisting on the unaffected side with no other support.

The physiotherapist takes the weight of the patient by supporting the forearm on her hip and leaning away whilst she puts one arm under the shoulder joint and supports the patients hand in her other hand. This is a case of balancing body weight, and a good, wide, steady stance is necessary.

(4) Not assisted.

Patient walking by herself with a 4-legged stick.

Body balance and arm swing should now be corrected. The patient should be taught to flex the knee and hip and to swing the leg forward in a straight line, putting the heel on the ground first, instead of the usual, typical pelvic tilt and semi-circular swinging action.

Apparatus to regain strength and mobility:

The "Exercycle" is a small but very useful piece of appararatus, consisting of only the crankshaft and pedals of a bicycle, an adjustable resistance and a distance guage. It can be used to mobilise and strengthen both the arms and the legs (by putting it on a table or on the floor).

For the legs it is placed against a wall and the patient is able to treadle it whilst sitting a little forward in her own chair.

Foot plates may be made or purchased, to fit over the pedals, and these have a heel stop and straps to keep the foot in position. Very good auto-assisted movements may thus be accomplished without distress to the patient.

(This apparatus may be purchased from Protea Holdings Ltd. Price $\mathfrak{E 6}$ 15s. 0d.)

\section{Later Stage:}

A suitable high chair for hemiplegics and others with stiff hip joints or lumbar spine deformities, who need to strengthen the quadriceps muscle or loosen the knee joints, may be made by a helpful carpenter. -

(It is noticeable that most patients make a bee-line for this chair in the department, where it takes up no extra room.)

See Diagram IVa

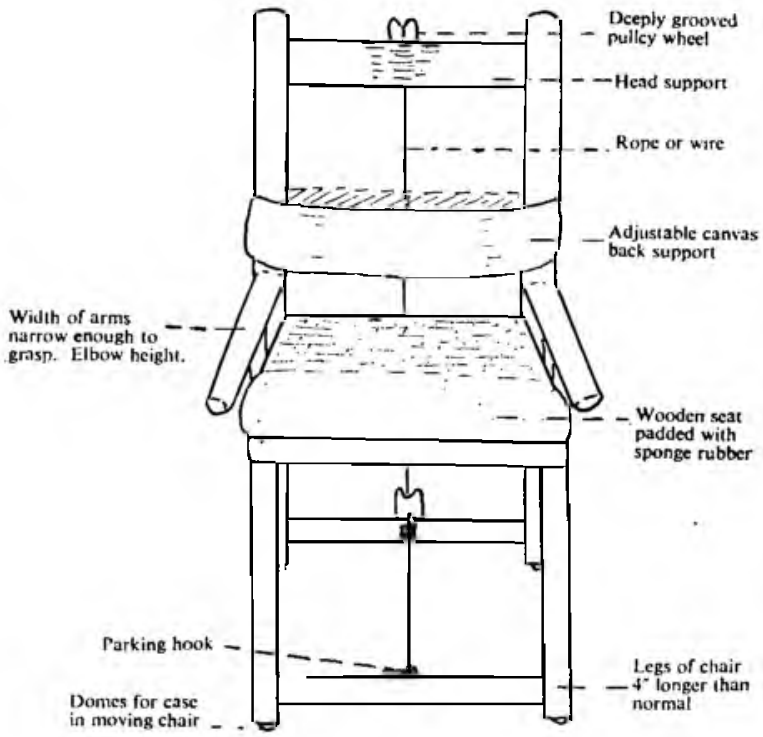

HIGH CHAIR for general use and Quadriceps resistance exercise.

Diagram IVa 

Specifications for the construction of high chair for quadriceps
exercise:

It should be made of strong solid wood, so that it is too heavy to tip over easily.

The legs: should be made 4 " longer than normal, of a The legs: shoure shape and joined by cross-bars 3 " above floor level. Domes may be inserted into the bases if desired.

The seat: This should be wide enough to accommodate the largest patient and it may be built up in front into a half-domed shape, to prevent the patient from sliding half-domeds and also to give leverage for muscle work. The whole surface of the seat may be covered with sponge rubber

The back: There are two upright struts fixed to the rear corners of the seat, extending to just above head height of average patient; they are joined together at the top by a thick crossbar, slightly curved for head support.

Sling: A broad piece of canvas is placed round these uprights and stitched to itself. This makes an adjustable back support and allows the patient with hip or lumbar deformities to sit in comfort.

The arms: These are made of unpadded wood, narrow enough to be gripped easily. They come forward from the uprights at elbow level, almost to the level of the front of the seat. There is a strong supporting strut to the side of the seat.

\section{See Diagram IVb}

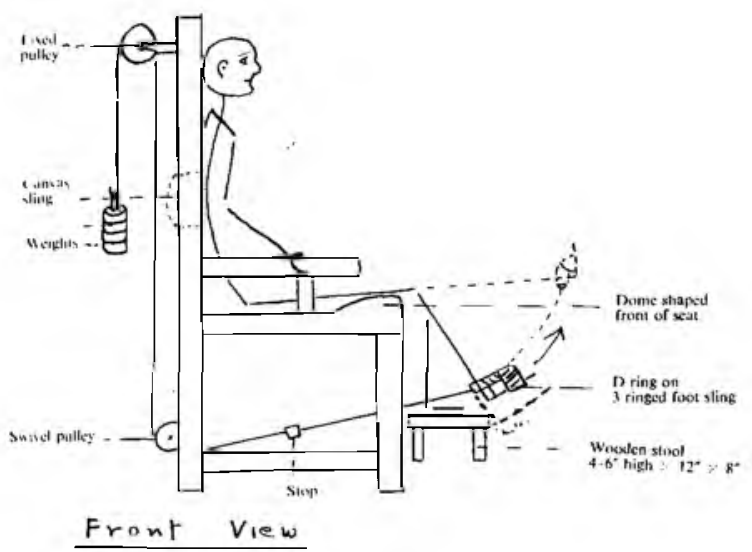

Apparatus for quadriceps work:

Fitted to this chair:

(1) At the middle of the back of the head crossbar, a strong, deeply grooved pulley wheel is firmly screwed in.

(2) At the middle of the back of the crossbar between the two rear legs of the chair, a swivel pulley is fixed so that it moves freely above the bar.

(3) A rope or metal cable is inserted between the pulleys with a hook on each end for attachment to (a) bag or rod holding weights, and (b) the D-loop on the patient's foot sling.

(4) A "cup-hook" is screwed into the back of the front crossbar and this saves the weight crashing to the floor and subsequent grovelling to pick up the rope.

(5) A three-ringed foot sling is put round the patients foot and ankle with the D-ring at the heel.

(6) A small but strong wooden stool, 4-6" high, 12" long and 8 " wide is put under the foot not being exercised. This also assists getting on and off the chair. These stools have many other uses in a department.
Adjustments: The range of movement required must decide the precise point of attachment of the weights.

If the rope is too long, the weight touches the ground; if it is too short it is stopped by the upper pulley wheel before the patient has fully extended her knee.

A stopper may be put on the rope under the chair to prevent too much knee flexion.

These practical pieces of apparatus have been evolved as a result of seven years single-handed work, mostly with hemiplegics, building up from nothing to geriatric units in England. Though heavy, the results of this work were very satisfying. Now these departments are properly established and run by a chartered physiotherapist, a remedial gymnast (male), two assistant nurses and a porter in each hospital.

\section{DOES YOUR WHEEL CHAIR FIT?}

\section{MISS M. HUMPHREY, B.Sc.(PHYS.) WITS.}

How often have you given or received this request "Please order a wheel-chair for this patient". No more-no less.

Do you KNOW why some chairs have the large wheels in front and some at the back?

Do you KNOW that a wheel-chair without brakes is a dangerous vehicle?

Do you KNOW that wheels of 5 in. or less can be positively lethal?

Do you KNOW that there are many makes on the market and that the manufacturers of a good and reliable make are only too ready to make any adjustment you may require?

A wheel-chair is like any orthopaedic appliance worn by a patient and should be ordered with just as much care. The patient's disability, weight, age and sex are all important factors to be taken into consideration when it is prescribed. For it stands to reason that if it is necessary to order a wheelchair for a petient it is going to be a pretty permanent essential for the rest of his life. As he is likely to spend a great deal of time in the chair it must measure up to his specific requirements. It must be comfortable. It must be easily manoeuvreable, it must be built in such a way as to facilitate transfer with the minimum of physical effort and above all it must be as safe and stable as a wheel-chair can possibly be.

\section{WHEELS}

All models should have two large and two'small wheels.

Whether the large wheels are at the front or back depends largely on the patient's disability.

Large wheels should have a diameter of 23 in.; small wheels 8 in.-not less, as smaller wheels are more likely to become entangled in rugs, cracks and small objects.

\section{HANDRIM PROJECTIONS}

Horizontal, vertical or diagonal projections may be attached to the handrims.

The number, length, and the desired spacing should be specified.

The projections are indicated for patients who have shoulder muscle power, but no power in the hands.

\section{TYRES}

The tyres on the standard models are of solid rubber but pneumatic tyres may be prescribed to make riding easier.

\section{BRAKES}

Every chair should have brakes to prevent rolling on an incline or when the patient desires to get out of the chair without its being held by another person. The brakes must be within easy reach, and if arm rests are removable, must be low enough so they do not interfere with moving sidewards out of the chair. Removable extension attachments should be prescribed with the removable arm rests. 